\title{
Influências da Remuneração de Executivos na Congruência de Metas
}

\author{
The Influence of the Executive Remuneration in the Congruence of the Goals
}

\section{José Carlos Tiomatsu Oyadomari}

Doutor em Ciências Contábeis pela Universidade de São Paulo

Professor do Programa de Pós-Graduação em Ciências Contábeis da Universidade Presbiteriana Mackenzie

Endereço: Rua da Consolação, 896, prédio 60

CEP: 01302-907 - São Paulo/SP Brasil

E-mail: oyadomari@mackenzie.br

Telefone: (11) 2114-8273

\section{Ana Maria Roux Valentini Coelho Cesar}

Doutora em Administração pela Universidade de São Paulo

Professora do Programa de Pós-Graduação em Ciências Contábeis da Universidade Presbiteriana Mackenzie

Endereço: Rua da Consolação, 896, prédio 60

CEP: 01302-907 - São Paulo/SP Brasil

E-mail: rouxcesar@mackenzie.br

Telefone: (11) 2114-8273

\section{Eliane Ferreira de Souza}

Bacharel em Ciências Contábeis pela Universidade Presbiteriana Mackenzie

Pesquisadora voluntária do Núcleo de Estudos em Controladoria - NECO

Consultora da Defensor \& Associados Consultoria em Gestão Empresarial

Endereço: Rua Antônio Macedo, 339

CEP: 03087-010 - São Paulo - SP BRASIL

E-mail: eliane@defensoreassociados.com.br

Telefone: (11) 2098-2034 Ramal 27

\section{Magda Aline de Oliveira}

Bacharel em Ciências Contábeis pela Universidade Presbiteriana Mackenzie

Pesquisadora voluntária do Núcleo de Estudos em Controladoria - NECO

Endereço: Rua da Consolação, 896, prédio 60

CEP: 01302-907 - São Paulo/SP Brasil

E-mail: Mag.ali@ig.com.br

Telefone: (11) 2114-8273

Artigo recebido em agosto de 2009. Passou por uma avaliação double blind review em novembro de 2009. Aceito em dezembro de 2009 pela Editora Científica Sandra Rolim Ensslin. Artigo apresentado no II Congresso ANPCONT, 2008, SALVADOR, 2008. 


\title{
Resumo
}

Este estudo tem o objetivo de identificar quais são as práticas de remuneração variável adotadas pelas empresas e como as metas de remuneração estão atreladas às metas oriundas do Sistema de Controle Gerencial e, também, se há congruência entre as metas individuais e organizacionais. O estudo foi desenvolvido junto a 21 empresas de grande porte, a maioria pertencente ao ranking dos 200 maiores grupos econômicos do Brasil, feito pelo Valor Econômico. Os resultados obtidos sugerem que: 1) a remuneração variável, com metas individuais, está associada ao alcance das metas organizacionais; 2) as práticas adotadas pelo mercado para a remuneração variável têm peso diferenciado em termos de influência sobre o comportamento do gestor; 3) o conflito de agência pode se apresentar se as metas individuais não foram associadas às metas globais da organização; 4) o sistema de remuneração variável tem um efeito motivador na busca por desempenho.

Palavras-chave: Remuneração Variável, Congruência de Metas, Contabilidade Gerencial.

\begin{abstract}
This study has the aim of identifying which variable remuneration practices are being used by the companies and how the remuneration goals are linked to the goals derived of the Management Control System and also, if there is coherence between the individual and organizational goals. The study was developed within 21 big companies, the majority part of the ranking of the biggest 200 economical groups, ranked by "Valor Econômico". The obtained results show: 1) the variable remuneration, with individual goals, is linked to reaching the organizational goals; 2 ) the adopted practices by the market for the variable remuneration has a different power talking about the managerial behavior; 3 ) the action conflict can be shown if the individual goals have not associated to the global goals of the organization; 4) the variable remuneration system has a motivating in the search of the a performance.
\end{abstract}

Key words: Variable Remuneration, Goals Congruence, Management Accounting.

\section{Introdução}

A busca por desempenhos econômicos superiores à média da indústria é presente nas organizações. A Estratégia, como campo do conhecimento, buscando entender como as organizações obtêm e mantêm vantagem competitiva sustentável, operacionalizada por desempenho econômico superior, identificou que os recursos possuídos pelas empresas explicam melhor a diferença de desempenho do que a escolha de um posicionamento na cadeia de valor (VASCONCELOS e BRITO, 2004). Dentre esses recursos podem-se citar as pessoas como sendo uma fonte de vantagem competitiva (BROOKING, 1996); entretanto, para que essas pessoas gerem valor para o negócio é necessário que elas sejam motivadas a atingir as metas organizacionais. Ocorre que, muitas vezes, as metas pessoais podem não estar em consonância com as metas organizacionais, provocando assim o que os autores chamam de não congruência de metas. O problema se agrava ainda mais quando há uma política de remuneração variável que estimula o alcance das metas, quando estas não são congruentes.

Para assegurar que o comportamento e as decisões dos subordinados sejam consistentes com os objetivos e estratégias organizacionais, as organiza- 
ções utilizam-se do Sistema de Controle Gerencial SCG (MERCHANT e VAN DER STEDE, 2007; ANTHONY e GOVINDARAJAN, 2002; HORNGREN, SUNDEN e STRATTON, 2004). Tradicionalmente as organizações definem metas e objetivos ao final do planejamento estratégico e processo orçamentário, entretanto não basta ter apenas metas e objetivos definidos, é necessário que as pessoas sejam motivadas a atingi-las. Para estimular os empregados a cumprir os objetivos e metas surgiram vários procedimentos para gestão de pessoas, dentre eles o sistema de remuneração variável, o qual propõe que parte do salário seja associada ao nível de contribuição do funcionário à organização, ou seja, torna-se mais clara, para o empregado, a relação entre o desempenho e o reconhecimento pela organização. Mas partindo da premissa que a remuneração variável estimula o alcance das metas, torna-se relevante identificar se estas metas, as quais são base da remuneração variável, são congruentes em nível organizacional, ou seja, se estão alinhadas entre as metas individuais dos executivos e as metas globais da empresa.

Desta forma a questão de pesquisa que esse estudo pretende responder é: como a remuneração variável atrelada às metas individuais está associada com o alcance das metas organizacionais, indicando congruência de metas? Outra questão adicional é: será que as metas vinculadas à remuneração variável, se atingidas, colaboram para o atingimento das metas globais da empresa? Este estudo tem como objetivos específicos: 1. identificar quais são as práticas de remuneração variável adotadas pelas empresas; 2. identificar se as metas de remuneração estão atreladas às metas oriundas do $\mathrm{SCG}$; 3. analisar se há congruência entre as metas individuais e organizacionais.

Consoante Demo (2000, p.73) reconhece-se o "caráter intricado da realidade", o qual exige estudos interdisciplinares, assim esse estudo aplicado sobre a contabilidade gerencial utiliza-se de conhecimentos oriundo da área de recursos humanos. A contribuição desse estudo, de natureza exploratória, é gerar maiores conhecimentos sobre o tema tão pouco estudado no Brasil, embora internacionalmente já venha sendo discutido com maior freqüência. Nesse sentido buscou-se: (i) identificar os programas de práticas de remuneração variável no tocante a: representatividade, abrangência (diretoria, gestores), nível percentual da remuneração variável que é representado por atingir as metas globais da empresa, (ii) verificar se a remuneração variável depende de metas conjuntas; (iii) identificar se as metas da empresa são provenientes do Sistema de Controle Gerencial

\section{Fundamentação Teórica}

\subsection{Sistema de controle gerencial, incentivos e congruência de metas}


O Sistema de Controle Gerencial (SCG) é o sistema que a alta administração utiliza para controlar as atividades da organização, o comportamento e as decisões dos empregados e para observar se as mesmas são executadas de acordo com as estratégias organizacionais (ANTHONY e GOVINDARAJAN, 2002; MERCHANT e VAN DER STEDE, 2007) Merchant e Van der Stede (2007, p.29) relacionam quatro principais etapas na implementação de um SCG: primeiro, a organização deve definir as dimensões de desempenho esperadas e as não desejadas (lucro, retorno, satisfação de clientes, etc.); segundo, é necessário identificar como essas dimensões devem ser mensuradas ou medidas; terceiro, deve estabelecer metas para essas dimensões; e por último, devem ser criados incentivos para influenciar o comportamento dos gestores a atingirem essas metas.

Reconhecendo o papel das pessoas na execução do Sistema de Controle Gerencial, alguns aspectos devem ser considerados como pontos fundamentais de um SCG: (i) os indivíduos, geralmente, agirão em prol de seus interesses pessoais, desta forma, o SCG deve ser desenhado de forma a obter vantagens, tendo em vista este comportamento humano; (ii) devem ser alinhados os objetivos dos colaboradores com os objetivos da organização, implementando incentivos que promovam a congruência de metas (HORGREN, SUNDEM e STRATTON, 2004, p.319)

A congruência de metas é alcançada quando os colaboradores, que estão comprometidos com as suas próprias metas, também tomam decisões em prol das metas gerais da organização (HORGREN et al., 2004). Anthony e Govindarajan (2002) também afirmam que é função do Sistema de Controle Gerencial assegurar a congruência de objetivos. Portanto se conclui que um dos principais propósitos do controle gerencial é assegurar a congruência de metas, ou seja, que os planos estabelecidos pela empresa sejam projetados de um modo que, à medida que seus colaboradores atinjam suas metas próprias, estejam colaborando, direta ou indiretamente, para o atingimento das metas da empresa.

\subsection{A congruência na definição das metas}

As metas organizacionais e das áreas são definidas geralmente como fruto do processo orçamentário. Para Anthony e Govindarajan (2002), o orçamento compreende alguns aspectos comportamentais por motivar seus gerentes a elaborar e executar as metas eficazes e eficientemente através da: participação no processo orçamentário, análise do grau de dificuldade das metas do orçamento e envolvimento com a alta administração. Segundo Anthony e Govindarajan (2002, p.476), a participação dos gerentes na elaboração do orçamento provoca motivação por dois motivos: (1) A aceitação das metas orçamentárias e o empenho dos gerentes em cumpri-las são maiores, pois as mesmas não foram impostas pela 
alta administração; (2) A participação dos gerentes na elaboração do orçamento promove a troca de informações importantes entre os diversos setores. Quanto à definição de metas Garrison e Noreen (2001, p.264) afirmam que os programas orçamentários mais bem-sucedidos são os que adotam o método de "baixo para cima", principalmente se o orçamento for utilizado como base para a avaliação dos gerentes.

Em contraposição, Jensen (2003) argumenta que o uso dos orçamentos para definir remuneração destrói valor e que os orçamentos estimulam comportamentos disfuncionais na definição das metas orçamentárias. $\mathrm{O}$ autor, embora admita a existência do orçamento para planejamento, advoga o fim do uso do orçamento para o sistema de recompensa de executivos, mostrando assim outra visão sobre o sistema de remuneração variável.

\subsection{Teorias da motivação}

A discussão sobre a influência de fatores que aumentem a motivação para o desempenho não é recente. Discute-se o fenômeno da motivação desde os primórdios da teoria de administração, com os achados de Elton Mayo e até hoje não se tem uma posição conclusiva ou excludente sobre o assunto. Há diferentes correntes teóricas, cada uma delas baseada em algum enfoque conceitual e filosófico, com foco em algum aspecto do fenômeno da motivação e que, portanto, explicam apenas parte do problema. Revisando trabalhos publicados sobre motivação, Perry e Porter (1982 p. 91) apontam que os mesmos apresentam uma multiplicidade de fatores que afetam a motivação, fatores estes que podem ser agrupados em quatro categorias: a dos fatores individuais, onde se enquadram os trabalhos que fazem referência aos diferentes tipos de necessidades e aos níveis de satisfação das mesmas nas situações de trabalho; a dos fatores de trabalho, onde aparecem os estudos que incluem a avaliação do desempenho individual, a clareza dos objetivos de trabalho e o grau de desafio proposto pelo trabalho enquanto relacionados à motivação; a dos fatores relacionados ao ambiente interno, onde são vistos estudos que se referem à relação do trabalhador com seus pares e com seu supervisor, aos sistemas de recompensa, à diversidade de valores dentre grupos de trabalho e ao clima organizacional; e os estudos que apresentam fatores relacionados ao ambiente externo, que afetam a empresa e os trabalhadores e sobre os quais as empresas não têm controle, como variáveis políticas, econômicas, demográficas, tecnológicas. A remuneração variável está associada aos fatores individuais e de trabalho.

As abordagens clássicas mais conhecidas no meio organizacional, que consideram as necessidades dos sujeitos enquanto fatores motivacionais (estudo de fatores individuais), são as teorias de Maslow e Herzberg. Maslow classifica 
as necessidades humanas em dois grupos básicos: necessidades primárias (físicas ou sociais, consideradas praticamente universais porque associadas à manutenção da vida) e necessidades secundárias (mais fortemente condicionadas pela experiência do sujeito), que devem ser satisfeitas segundo uma hierarquia (DAVIS e NEWSTROM, 1992). Para Maslow a motivação está claramente associada a um propósito, ou objetivo, que incomoda a pessoa até que seja atingido; assim sendo, a necessidade é intrínseca ao indivíduo e sua privação mobiliza o sujeito para busca de sua satisfação. Além disto, para o autor, determinação e motivação são conceitos distintos: determinação pode ser não motivacional, como a ação de certas condições que levam a certos comportamentos do sujeito (seriam os fatores relacionados ao ambiente externo); os motivos não são determinantes de comportamentos porque são mediados pela consciência do sujeito; entretanto, são mobilizadores do comportamento do indivíduo, que então busca objetivos e objetos para satisfazê-los (SAMPAIO, 2004, p. 4). Para Maslow as necessidades são organizadas em sete grupos (fisiológicas, de segurança, de pertencimento e amor, de estima, de auto-realização, de saber e entender, estéticas) (SAMPAIO, 2004), embora no meio organizacional não sejam comumente consideradas as necessidades de saber e entender, e as estéticas. Essas necessidades foram classificadas por Maslow como necessidades superiores e inferiores, no sentido de que à medida que são satisfeitas as necessidades fisiológicas, por exemplo, outras necessidades emergem para mobilização do comportamento do sujeito. Entretanto, Maslow defende a idéia de múltipla motivação, ou seja, fala da preponderância de algumas necessidades sobre outras em determinados momentos, mas não de uma hierarquia que seja rigidamente determinada.

Herzberg parte da classificação de necessidades feita por Maslow e levanta um aspecto interessante para a discussão sobre motivação: satisfazer necessidades básicas não significa motivar, apenas evita a insatisfação; isto porque, para Herzberg, o oposto de satisfação não é insatisfação, mas sim nenhuma satisfação; do mesmo modo, o oposto de insatisfação não é satisfação, e sim nenhuma insatisfação (HERZBERG, 1997). Comparando-se as posições de Herzberg e Maslow, vê-se que Herzberg considera que haja fatores de motivação e que estes estão relacionados às necessidades de reconhecimento, de realização, de possibilidades de crescimento e de reconhecimento, ou seja, o atendimento das necessidades de nível superior proposto por Maslow é que poderia efetivamente levar à motivação do sujeito; o atendimento às demais necessidades apenas impediria sua desmotivação.

Outra linha de discussão sobre motivação é proposta por Archer (1997), que desloca a ênfase da discussão das necessidades para os fatores que satisfazem estas necessidades. Para Archer é impossível a identificação das necessidades dos sujeitos, pois estas são intrínsecas e portanto, não diretamente observáveis, até 
porque as necessidades se apresentam de maneira combinada e torna-se difícil (ou impossível) tentar identificar qual delas mobiliza o sujeito em direção a um objetivo específico. Assim, o autor propõe a identificação de fatores (intrínsecos ou extrínsecos) que satisfazem o sujeito (diminuindo necessidades), ou contrasatisfazem o sujeito (criando novas necessidades); desta forma a questão da motivação está firmemente ligada ao controle de fatores externos ao sujeito que o levem a se sentir satisfeito ou contra- satisfeito. Nesta visão, pessoas perfeitamente satisfeitas não estão motivadas.

Esta discussão é bastante importante quando se aborda a questão de alcance de metas como pré-condição para ganho de remuneração ou de outros fatores de satisfação. Se as pessoas atingirem as metas, e não tiverem mais nada que as desafie, estarão desmotivadas para o trabalho. Assim, o grande desafio de um plano de metas está em delinear objetivos que sejam percebidos como exeqüíveis, e uma medida coerente para avaliar o desempenho dos colaboradores. Anthony e Govindarajan (2002), consideram que sejam metas exeqüíveis aquelas que têm 50\% (cinqüenta por cento) de chance de serem atingidas por um gerente com desempenho razoável. Garrison e Noreen (2001) relatam que se as metas são muito altas e os colaboradores as perceberem como irrealistas, a motivação será prejudicada; se as perceberem como muita folgadas, ocorrerá desperdício. Se bem delineadas, o alcance das metas levaria à liberação de fatores que satisfariam as necessidades das pessoas (não importa de qual nível, até porque é praticamente impossível, numa organização, determinar qual necessidade está controlando o comportamento das pessoas em determinados momentos). Por outro lado, essas metas precisam ser constantemente revistas, pois é preciso criar fatores de contra-satisfação, ou seja, criar níveis de desafio, ou de desequilíbrio. Num programa de metas, seria o desenvolvimento contínuo de objetivos a serem atingidos em períodos menores do que o exercício fiscal de um ano, por exemplo. Metas exigidas em intervalos de tempos muito grandes levam ao aumento da busca de resultados apenas perto dos momentos de liberação dos fatores de satisfação (WEITEN, 2002). Além disto, como apontam Anthony e Govindarajan (2002), a alta administração não deve aumentar as metas do orçamento para o ano seguinte quando seus gerentes ultrapassam as metas estabelecidas, pois estes podem não se esforçar para atingirem suas capacidades máximas para evitarem as metas demasiadamente altas para os exercícios seguintes. Para garantir que as metas orçamentárias sejam exeqüíveis, Anthony e Govindarajan (2002) propõem a participação dos gerentes na elaboração do orçamento, pois neste caso a aceitação das metas orçamentárias e o empenho dos gerentes em cumpri-las seriam maiores, vez que as metas não foram impostas pela alta administração. Além disto, propõem que, sempre que as metas sejam superadas, haja algum tipo de incentivo que "puxe" o nível de desempenho para patamares cada vez mais 
elevados (ANTHONY e GOVINDARAJAN, 2002).

Entretanto, quando se pensa em sistemas de remuneração como um dos fatores que podem estar associados à motivação para o alto desempenho, devese considerar que oferecer ganhos diferenciados associados ao alcance de metas não garante, por si, o bom desempenho. As pessoas analisam quanto querem uma determinada recompensa (valência), mas também analisam se o seu nível de competências será adequado para alcançarem o nível de desempenho esperado (expectativa); além disto, analisam se a recompensa estará, de fato, disponível, caso alcancem os patamares de desempenho esperados (VROOM, 1964). A teoria da expectativa de Vroom propõe que a mobilização em direção a um dado objetivo (motivação) é resultante dessas considerações sobre valência, expectativa e instrumentalidade, feitas em conjunto.

Neste trabalho considera-se que a motivação seja uma predisposição do sujeito (uma atitude) e, como tal, depende da análise que o sujeito faz em relação ao objeto da atitude (no caso, o programa de remuneração variável). $\mathrm{O}$ alcance dos objetivos da organização, traduzidos em alcance de metas orçamentárias, só será alcançado se: 1 . as metas representarem para o sujeito fatores de contrasatisfação, ou seja, apontarem um desnível entre a situação atual e a desejada; 2 . se as metas forem percebidas pelos sujeitos como exeqüíveis, ou seja, em patamares passíveis de serem atingidos considerando-se os seus recursos e suas habilidades disponíveis (expectativa); 3. se as pessoas que recebem as metas considerarem que os níveis de remuneração a elas atrelados sejam interessantes (valência) para poderem se converter em satisfação de necessidades (primárias ou secundárias); 4. se houver a certeza de que, uma vez cumpridas as exigências, as recompensas de fato serão liberadas (instrumentalidade).

\subsection{Sistema de incentivos}

Segundo Horngren et al. (2004), e de acordo com a teoria de Vroom, vincular recompensas ao desempenho gerencial é a forma mais adequada de remunerar, pois fornece ao gerente incentivo para atuar em prol da congruência de metas. Mas, conforme já discutido, vários fatores estão associados à predisposição desses funcionários para cumprir as metas que lhe são propostas e o grande problema que se coloca para as empresas é descobrir quais são os fatores que efetivamente motivam os funcionários para o desempenho e nível de excelência (HORNGREN et al., 2004). Merchant e Van der Stede (2007) elencam que os incentivos devam ser valiosos, impactantes, compreensíveis quanto à forma de obtenção e aos próprios valores, oportunos em relação ao momento de ser concedido, com efeitos duradouros, reversíveis de forma a evitar a agregação permanente na remuneração e eficientes em custos. 
Na definição das metas que constituem um contrato, os gestores e a organização devem ter plena concordância de como as recompensas e as medidas de desempenho se relacionarão. Desta forma, conforme citado por Lopes (2004), busca-se o funcionamento harmonioso da organização, onde a empresa é vista como um contrato e todos os participantes contribuem com algo para firma, recebendo a parte que lhe é cabível, de acordo com o contrato. Mas geralmente essa relação não é harmoniosa; Lopes (2004) diz que o conflito da agência ocorre quando os gerentes colocam seus próprios interesses, divergentes dos interesses da empresa, em primeiro lugar. Lopes (2004, p. 175), determina ainda que para redução do impacto do conflito de interesses entre gerentes e acionistas, deve-se utilizar a remuneração variável, tornando o gerente um pouco "acionista". Para Horngren et al. (2004), os contratos compreendem três fatores: (i) incentivo: o gerente sempre maximizará a medida de desempenho que possuir maior influência em sua remuneração, portanto, a alta administração deve optar por uma medida de desempenho promovedora da congruência de metas; (ii) risco: quanto maior o risco do gerente, maior deve ser a sua recompensa, pois a influência de fatores incontroláveis será maior sobre a mesma; e (iii) custo de mensurar o desempenho: é dispendioso medir diretamente o desempenho do gerente.

Sistemas de incentivos têm fortes impactos sobre o desempenho dos empregados, mas também sobre a competitividade de uma empresa. Mas incentivo é mais do que salário pago ou bônus. Inclui compensação intrínseca ou psíquica, como status, independência, poder (IVANCEVICH, 2007). Assim, pode-se dizer que o tema é extremamente complexo e pode ser analisado sob diferentes ângulos.

Do ponto de vista puramente econômico, o trabalho é uma commodity onde o empregador compra certa quantidade de trabalho do empregado ao preço estabelecido pelo mercado. A questão está em como se estabelecer o valor de unidades de trabalho. Além disto, modelos econômicos freqüentemente posicionam que o salário é o fator motivador, ou seja, desconsideram questões relacionadas à vontade do empregado de estar no trabalho, a habilidade do mesmo em se manter empregado, a auto estima relacionada ao emprego e às atividades lá desenvolvidas, dentre outras.

\subsubsection{Programas de Remuneração Variável}

São alguns programas de remuneração variável: remuneração por unidade produzida; incentivos salariais por mérito; participação nos lucros e participação nos resultados; bônus de produtividade; incentivos grupais; stock options, dentre outros (ROBBINS, 2004; IVANCEVICH, 2007; MILKOVICH; BOUDREAU, 2000).

No plano de incentivos por mérito, a remuneração do trabalhador aumenta 
de acordo com o aumento de seu desempenho quando comparada com a de um período de tempo anterior (IVANCEVICH, 2007; MILKOVICH e BOUDREAU, 2000); este tipo de remuneração combina três elementos entre si: (i) avaliação do desempenho individual; (ii) faixas salariais fixadas para refletirem as diferenças no desempenho pessoal; e (iii) critérios para o aumento do mérito. Os autores citam que existem alguns problemas identificados neste tipo de remuneração: se o mérito é mal administrado, nos casos em que a avaliação do desempenho é anual, os colaboradores, muitas vezes não associam o aumento de hoje com o desempenho de meses anteriores.

Na remuneração por unidade produzida, o colaborador recebe o seu salário de acordo com cada unidade que produz (ROBBINS, 2004; IVANCEVICH, 2007); na remuneração por habilidades, o colaborador é remunerado pela quantidade de tarefas diferentes que possa desempenhar em função do número de habilidades (certificadas) que possua (ROBBINS, 2004; IVANCEVICH, 2007); no pagamento de bônus, este é liberado quando um trabalhador excede o padrão de desempenho esperado (IVANCEVICH, 2007); na participação nos lucros, a empresa distribui um percentual fixo do lucro total da organização para todos os empregados, sem distinção de níveis individuais de desempenho (MILKOVICH; BOUDREAU, 2000; IVANCEVICH, 2007); na participação nos resultados (ROBBINS, 2004), o ganho adicional está relacionado aos resultados e à produtividade de empresa como um todo ou de alguma área em especial.

Dentre os programas de compensação não monetários tem-se: programas de reconhecimento de funcionários (ROBBINS, 2004), que ligam a motivação dos colaboradores ao trabalho; neste caso os funcionários são compensados por palavras, elogios em público, brindes, folgas remuneradas ou de outras maneiras; programa de envolvimento dos funcionários (ROBBINS, 2004).

\subsection{Tensões geradas pelo uso de medidas de desempenho atreladas à remune- ração variável}

Essa seção é desenvolvida com base no conceito de tensões dinâmicas formulado por Simons (2000).

\subsubsection{Tensão entre curto prazo x longo prazo}

A utilização do Retorno sobre Investimento ROI como base para remuneração variável pode motivar a não congruência de metas, por exemplo, um gestor pode avaliar ser necessário fazer um investimento em uma determinada data, porém, se esses recursos ainda não geraram resultados nesse período, isso implicará em uma provável queda na taxa do ROI, desta forma o gestor pode se 
sentir tentado a buscar seus interesses de curto prazo, que é obter a remuneração variável; assim, ele deixaria de fazer o investimento, podendo sacrificar a obtenção de resultados no médio e longo prazo. Por isso se argumenta que o ROI é um indicador que mede o desempenho de curto prazo como discutido por Merchant e Van der Stede (2007) e para ser utilizado é sugerido que o ROI seja medido em um horizonte temporal maior de três a seis anos; a única dificuldade dessa proposta é a questão do turnover dos executivos em um tempo menor.

Outro exemplo desta tensão decorre geralmente dos gestores das áreas comerciais, os quais são remunerados com base no valor das vendas, mas que necessariamente não estão atingindo os objetivos de lucratividade pretendidos pela organização. Mesmo a meta de Margem de Lucro pode induzir os gestores operacionais a não fazer determinados gastos e com isso comprometer a qualidade dos processos operacionais. Por outro lado, sem uma medição no curto prazo, a organização corre o risco de fazer gastos desnecessários, configurando assim esta tensão entre objetivos de curto e de longo prazos.

\subsubsection{Tensão Cooperação versus Competição}

Como as grandes corporações se dividem em unidades de negócio, competindo por recursos, prestígio e remuneração, esta tensão é bastante presente na vida organizacional. Uma possível solução é a utilização de remuneração variável baseada em metas cruzadas, ou seja, a remuneração de uma área organizacional está atrelada ao alcance de metas de outra área organizacional. Essa prática pode propiciar vendas compartilhadas e também compartilhamento de recursos. Merchant e Van der Stede (2007) advogam que a remuneração baseada no desempenho do grupo pode funcionar como uma espécie de controle cultural, já que estimula o monitoramento mútuo de desempenho, por meio das pressões que os membros do grupo exercem sobre os demais membros a alcançar as metas. Se por um lado, a cooperação pode estimular o desenvolvimento de esforços conjuntos, ela também pode gerar um grau de acomodação dos gestores das áreas organizacionais com baixo índice de desempenho, os quais pegariam "carona" no desempenho das outras áreas. Portanto, um balanceamento de metas individuais e globais talvez possa evitar esses comportamentos disfuncionais.

Etherington e Tjosvold (1998) apontam esses dois tipos de processo, o cooperativo e o competitivo, no ambiente cooperativo os gestores acreditam que suas metas são positivamente relacionadas e que o sucesso de um está relacionado ao sucesso dos outros. No processo competitivo, as pessoas acreditam que suas metas são negativamente relacionadas, ou seja, o alcance das metas de um departamento contribui para que o outro diminua a possibilidade de alcance de suas metas. Espera-se que interdependência de objetivos impacte a natureza das 
discussões do processo orçamentário e, sob um contexto democrático de discussões abertas, pode ser facilitada a aceitação do orçamento e a harmonização dos objetivos organizacionais (ETHERINGTON e TJOSVOLD, 1998).

De acordo com o exposto, vê-se que há autores como Osterloh e Frey (2002) e Ivancevich (2007) que chamam a atenção para o fato de que, embora a remuneração com base em desempenho seja importante, o sistema de remuneração deve contemplar uma ampla avaliação das pessoas e a recompensa monetária não pode ser a única variável a ser considerada, e outros fatores, especialmente os comportamentais e psicológicos, devem ser considerados.

\section{Procedimentos Metodológicos}

O estudo foi de natureza exploratória, vez que há poucos trabalhos publicados no meio acadêmico sobre o tema (pesquisa feita em anais de congressos e revistas nacionais). População prevista para o estudo: os 200 maiores grupos econômicos do país listados pela publicação "Valor 200 Maiores Grupos" do Jornal Valor Econômico de 2007. Da amostra foram selecionados 57 grupos; desses, 19 aceitaram participar, sendo os respondentes, em sua maioria, gestores das áreas de Recursos Humanos. Foram incluídos na amostra mais dois respondentes que se prontificaram a participar do projeto, mas cujas empresas não estão dentre a população prevista. Os dados a eles referentes foram mantidos, pois embora as empresas não sejam grandes grupos, são organizações que mantêm programas de remuneração variável consolidados.

$\mathrm{O}$ instrumento de coleta de dados foi desenvolvido especialmente para a pesquisa, de acordo com a literatura disponível sobre o tema. Um questionário foi disponibilizado em uma página eletrônica de modo a facilitar a captura de informações. As questões eram fechadas, e as respostas eram dadas na escala Likert (com notas variando de 1 a 7). Para captação da congruência de metas, foram delineadas 17 afirmativas sobre situações organizacionais e que indicam a congruência de objetivos e interesses do funcionário com os da organização, bem como o envolvimento dos empregados no delineamento das metas. Para identificação das práticas de remuneração e de seu entrelaçamento com os resultados da organização, foi apresentada uma lista de indicadores na qual os respondentes apontavam a freqüência de uso do indicador em sua organização. Os dados foram colhidos no segundo semestre de 2007.

\section{Análise e Discussão dos Resultados}

\subsection{Caracterização dos respondentes}


O questionário foi respondido em quase sua totalidade por vinte profissionais que atuam na área de Recursos Humanos e um da área de controladoria. Havia um filtro no questionário: uma pergunta inicial que identificava se o respondente estava envolvido na elaboração da política de remuneração variável; caso não estivesse, o respondente não faria parte da amostra. Os respondentes estavam distribuídos nos seguintes cargos: Gerente (nove), Supervisor (oito) e Assistente (quatro). Para o tempo no cargo/função verificou-se que 16 (dezesseis) estavam acima de três anos no cargo/função, 2 (dois) entre 1 e 3 anos, e somente 3 (três) há menos de um ano. Em relação à formação acadêmica dos respondentes, todos detêm nível superior e 15 detêm nível de pós-graduação Pela identificação demográfica dos respondentes vê-se que todos estão aptos e qualificados para responder o questionário, vez que se envolvem com a decisão das metas de remuneração e ocupam posições gerenciais e de staff.

\subsection{Caracterização das empresas}

As empresas que participaram da pesquisa estão distribuídas entre os seguintes ramos de atividade: 12 (doze) são indústrias, 7 (sete) pertencem ao ramo de serviços, 2 (duas) pertencem ao ramo financeiro. Quanto à estrutura societária, 9 (nove) são empresas de capital aberto, 6 (seis) são sociedades anônimas de capital fechado e 6 (seis) são limitadas. Quanto ao porte, 10 (dez) empresas têm mais de 3.000 funcionários, 5 (cinco) tem menos de 500 funcionários e 6 empresas têm entre 501 e 3.000 funcionários.

Quanto ao valor das receitas anuais em 2006, 1 (uma) empresa não informou a receita, 2 (duas) empresas têm receita menor que 100 milhões de reais, 5 (cinco empresas tem entre 101 milhões e 1 bilhão de reais, 8 (oito) empresas tem receita entre 1 e 5 bilhões de reais, e 2 (duas) empresas têm receita acima de 5 bilhões de reais e menos que 10 bilhões, e 3 (três) empresas têm receita acima de 10 bilhões de reais.

\subsection{Análise dos Resultados}

\subsubsection{Práticas mais utilizadas}

Para identificação do nível de utilização das práticas de remuneração variável nas empresas pesquisadas, foi adotada como escala Likert de 0 (zero) a 7 (sete), onde 0 (zero) representa a não utilização da prática, 1 (um) pouco utilização e 7 (sete) extrema utilização. A Tabela 1 apresenta as médias encontradas de nível de utilização encontradas para cada tipo de prática investigada. 
Tabela 1: Práticas de remuneração variável e utilização

\begin{tabular}{|l|r|}
\hline Práticas de Remuneração Variável & Média \\
\hline Participação nos lucros e resultados & 6,9 \\
\hline Remuneração por mérito & 4,3 \\
\hline Incentivos individuais & 3,0 \\
\hline Remuneração por unidade produzida ou vendida & 2,1 \\
\hline Plano de bonificações em ações (stock options) & 1,7 \\
\hline Recompensas não monetárias & 1,6 \\
\hline Prêmios em viagens e outros bens & 0,8 \\
\hline
\end{tabular}

Fonte: Dados da pesquisa.

Como esperado, por se tratar de executivos, a principal forma de remuneração variável é a participação nos lucros e resultados, o que está de acordo com o proposto por Robbins (2004, p. 185-188). O mesmo ocorre com a Remuneração por Mérito que, conforme Milkovich e Boudreau (2000, p.415-418), se baseia no desempenho individual dos gestores. Remuneração por unidade aparece com baixo nível de utilização, sugerindo ter pouca importância, o que é esperado, pois este tipo de remuneração é mais adequado para níveis operacionais. O baixo nível de utilização de stock options destoa da grande ênfase dada na literatura em relação a esse tipo de incentivo; entretanto, como a amostra é pequena, e só nove das empresas são de capital aberto, este resultado precisaria ser confirmado em estudos mais abrangentes do que este, de natureza exploratória. Consoante Merchant e Van der Stede (2007, p. 403), que afirmam que as recompensas têm que ser valiosas, encontrou-se baixo nível de utilização de recompensas não monetárias e prêmios em viagens ou outro bens, sugerindo que, para remuneração de executivos, recompensas não financeiras não são valorizadas.

\subsubsection{Utilização de metas oriundas do Orçamento e Planejamento Estratégico}

No tocante à utilização das metas globais vinculadas ao Orçamento/Planejamento Estratégico das empresas para a composição da remuneração variável, também foi adotada como métrica a escala de 0 (zero) a 7 (sete) citada no parágrafo acima. A Tabela 2 apresenta os resultados encontrados.

Conforme se vê na Tabela 2 é pequena a utilização da medida ROE, que segundo Assaf Neto (2006, p.120) mede a rentabilidade dos recursos aplicados na empresa pelos seus proprietários, e das medidas EVA e Valor de Mercado, definidas por Assaf Neto (2006, p. 180 e 183) como as medidas de criação de valor. O que pode explicar esse fato é o baixo uso das medidas EVA e o Valor de Mercado, embora seja de estranhar que o ROE embora bastante utilizado gerencial, não esteja sendo utilizado para remuneração variável. 
Tabela 2: Utilização das metas oriundas do Orçamento e Planejamento Estratégico

\begin{tabular}{|l|r|}
\hline Medida & Valor \\
\hline Lucro Líquido & 5,1 \\
\hline EBITDA (geração potencial de caixa) & 4,4 \\
\hline Vendas & 4,3 \\
\hline Satisfação de clientes & 3,2 \\
\hline Inovação & 2,1 \\
\hline ROE (Retorno sobre Patrimônio Líquido) & 1,6 \\
\hline Obter desempenho melhor que o concorrente & 1,1 \\
\hline EVA (Valor Econômico Adicionado) & 1,0 \\
\hline Valor de Mercado & 1,0 \\
\hline
\end{tabular}

Fonte: Dados da pesquisa.

Os demais resultados contrariam as pesquisas de Ittner et al. (1997, p.738) que afirmam que é predominante o uso de medidas não contábeis nos contratos de remuneração dos executivos. Também contraria a visão de Hope e Fraser (2003, p.109) que argumentam que o desempenho tem que ser comparado com o do concorrente.

Já a medida EBITDA, apesar das críticas quanto ao fato de não refletir adequadamente o desempenho das empresas (FREZATTI; AGUIAR, 2006, p.8) é o segundo indicador mais importante na composição da remuneração variável dos executivos.

\subsection{Análise do processo de definição de metas e aspectos comportamentais}

Para análise da forma como são definidas as metas, da existência de cruzamento de metas, de congruência de metas e de adoção de aspectos comportamentais na definição de metas, foram apresentadas aos respondentes frases assertivas, que deveriam indicar seu grau de concordância às mesmas numa escala Likert de 1 (discordo totalmente) a 7 (concordo totalmente). Apresentam-se a seguir os resultados encontrados para cada um desses aspectos.

\subsubsection{Definição das metas}

A assertiva "As definições das metas ocorrem em um processo imposto pelos acionistas" obteve a média de 3,4 indicando que o processo de definição das metas não é sempre top-down. Essa conclusão também é reafirmada pela resposta à assertiva "Ocorre um processo justo de negociação para definição das metas" que obteve uma média de 5,4. Os respondentes também consideraram que o "processo de definição de metas é justo", assertiva com média de 5,3. Outro resultado interessante é que os respondentes apontam que "não existem grandes 
diferenças entre metas atreladas ao programa de remuneração variável e as metas divulgadas internamente", já que a média da assertiva foi 3,0. Para as assertivas "diferenciação das metas por área ou nível hierárquico" e "o valor da remuneração variável oscila em função do grau de alcance das metas" obteve-se média 6,5; isto indica forte concordância, sugerindo que os programas de remuneração variável nas empresas pesquisadas são aplicados de maneira diferenciada, de acordo com o nível hierárquico, e são fortemente associados a cumprimento de metas.

\subsubsection{Metas departamentais, metas interdependentes e metas globais}

A assertiva "a remuneração dos gerentes está vinculada ao cumprimento de metas departamentais" obteve média de 5,8, enquanto a assertiva "a remuneração de um departamento é influenciada pelo alcance das metas de outro departamento" obteve média de 4,0; este resultado indica que a prática de metas cruzadas entre departamentos não é tão freqüente nas empresas dos respondentes. A assertiva "a remuneração dos executivos está vinculada ao alcance das metas globais da empresa" obteve média de 6,0 sugerindo que as metas globais da organização têm peso na remuneração dos executivos.

\subsubsection{Congruência de metas}

Para análise da congruência de metas a assertiva "quando os executivos atingem as metas pelas quais são responsáveis, a sensação deles é de que contribuíram para o alcance das metas globais da empresa" obteve a média 6,2 e a assertiva "atingir as metas globais da empresa significa que a empresa tem melhora de desempenho" obteve a média 6,0. Esses resultados indicam que há uma percepção de congruência de metas pessoais e organizacionais. Entretanto, a assertiva "quando os gerentes atingem as metas estipuladas para suas áreas, isso implica em dizer que os objetivos da empresa estão sendo necessariamente atingidos" obteve média de 4,3, mostrando uma possibilidade de conflito de metas dos respondentes com as metas organizacionais, consoante Etherington e Tjosvold (1998, p.142).

\subsubsection{Aspectos comportamentais}

A assertiva "os executivos têm clareza do que é necessário ser feito para obter a remuneração variável" obteve a média de 5,9, sugerindo que os comportamentos esperados para obtenção das metas são compreensíveis pelos executivos consoante Merchant e Van der Stede (2007, p 403). Duas assertivas foram propostas para avaliar se o sistema de incentivos direciona o comporta- 
mento dos executivos em busca dos resultados realizados; são elas: "o programa de remuneração variável de executivos é visto na empresa como uma forma dos executivos se esforçarem mais do que o fariam normalmente em prol dos objetivos da empresa", com média de 5,5, e "o programa de remuneração variável de executivos funciona como um catalisador dos esforços dos executivos em prol dos objetivos da empresa", com média de 5,7. As médias de alta concordância às assertivas sugerem que o programa de remuneração variável influencia, de alguma forma, o comportamento dos gestores em busca dos objetivos da organização, validando a afirmação de Anthony e Govindarajan, (2002, p.477); entretanto, as assertivas "as decisões dos gerentes são influenciadas pelas metas às quais estão vinculadas a remuneração", com média 4,7 e "percebe-se que muitas vezes as decisões dos gerentes são influenciadas para atingir metas que estão vinculadas à remuneração", com média 4,4, mostram indícios da existência do conflito de agência, conforme proposto por Lopes (2004, p. 171) e dos conflitos inerentes aos contratos de remuneração variável, conforme apresentado por Horgren et al. (2004).

\subsubsection{Representatividade da remuneração variável}

Com os resultados obtidos na pesquisa, verificou-se que 11 respondentes indicaram que a representatividade da remuneração variável na remuneração total anual dos executivos está entre $26 \%$ (vinte e seis por cento) a $50 \%$ (cinqüenta por cento), entretanto 5 (cinco) optaram por não responder esta questão. Os resultados, embora não sejam conclusivos, oferecem um parâmetro do nível de remuneração variável sobre a remuneração total, devendo este nível ser confirmado em estudos posteriores. Caso o parâmetro se mantenha em resultados posteriores, pode-se dizer que os programas de remuneração variável têm alto peso motivacional, vez que a possibilidade de obtenção de um alto nível de remuneração (a dimensão instrumentalidade, no modelo de Vroom), está fortemente associada ao empenho para alcance de meta (expectativa de desempenho, no modelo de Vroom) (VROOM, 1964, p. 21-27).

\subsubsection{Alcance das metas}

Em relação ao alcance das metas por parte dos executivos, 13 respondentes indicaram que as organizações para as quais trabalham têm atingido as metas no último ano, 5 (cinco) têm superado e apenas 3 não têm atingido. Analisou-se, em maior detalhe, as três empresas que não têm atingido as metas, de forma a se identificar diferenças. Três aspectos se destacaram: 1) a baixa utilização da "remuneração por mérito", que obteve média de 2,0 na escala de freqüência de utilização; 
2) a "definição das metas impostas pelos acionistas" com média de 6,0, indicando alta freqüência de utilização; 3) o alto índice de concordância com a assertiva "existem diferenças entre o programa de remuneração variável dos executivos e outras metas divulgadas aos executivos e demais gestores da empresa" com média 5,7. Os resultados sugerem que a não adoção de uma prática fundamentada na meritocracia contribui para índices baixos de desempenho; isto é coerente com a teoria do condicionamento de comportamento por utilização de reforço positivo, base das teorias sobre incentivos (WEITEN, 2002, p.176), bem como com a teoria de Herzberg, na qual o reconhecimento pelo desempenho é visto como forte fator de motivação (HERZBERG, 1997, p.178). Na definição de metas impostas pelos acionistas confirma-se a proposição de Anthony e Govindarajan (2002, p.475), para os quais um processo de definição de metas top-down tem menor efeito motivador. Já a existência de diferenças entre as metas vinculadas ao Programa de Remuneração Variável de Executivos e outras metas divulgadas aos executivos e demais gestores da empresa, sugerem que as metas não são claras, e que nem todos conhecem os fatores que influenciam a sua remuneração; isto confirma as proposições de Horgren et al. (2004, p. 300 e 302) para os quais as metas devem ser expressas em ações tangíveis, e a de Merchant e Van der Stede (2007) para os quais as metas individuais e organizacionais devem ser consonantes.

\section{Considerações Finais}

Este estudo apresentou resultados que sugerem que a remuneração variável, com base em metas individuais, está associada ao alcance das metas organizacionais. Pôde-se verificar que há uma série de práticas adotadas pelo mercado para a remuneração variável, e que estas têm peso diferenciado em termos de influência sobre o comportamento do gestor. Também se verificou que o conflito de agência pode se apresentar se as metas individuais não foram associadas às metas globais da organização. Identificou-se o efeito motivador do sistema de remuneração variável enquanto incentivo monetário para obter desempenho. A grande questão está na eleição dos patamares e no tipo de metas que são exigidos dos gestores, já que a remuneração variável pode responder por até $50 \%$ de sua remuneração geral. O estudo mostrou que as metas orçamentárias das áreas/ departamentos estão em conformidade com as práticas de remuneração variável, pois se direcionam para o desempenho individual. Entretanto, a relação entre as metas individuais e globais é muito sutil e sensível, se houver metas conflitantes aos objetivos da empresa não haverá congruência de metas. Este fato é claramente evidenciado neste estudo, principalmente pela concordância dos respondentes com as afirmativas: "As decisões dos gerentes são influenciadas pelas metas às quais está vinculada a sua remuneração" e "Percebe-se que muitas vezes as de- 
cisões dos gerentes são influenciadas para atingir metas que estão vinculadas à remuneração".

Além da vinculação das metas individuais às metas globais, outro fator relevante identificado no estudo foi o processo de definição destas, pois as empresas que têm atingido ou superado as metas promovem a participação dos gerentes neste processo, ao contrário das empresas que não têm atingido, onde as definições ocorrem em um processo imposto pelos acionistas. A sugestão de existência de uma relação positiva entre as práticas de remuneração variável e metas individuais e globais e o processo de definição das metas, é coerente com a teoria apresentada neste estudo. Nota-se, pelos resultados do estudo, a influência direta das práticas de remuneração variável e das metas provenientes do Sistema de Controle Gerencial, na congruência de metas. Por fim pode-se afirmar que os colaboradores quando remunerados em função de seu desempenho, trabalham em prol das metas individuais e das metas da empresa, desde que esta última busque equilibrar os interesses individuais e empresariais.

Esta pesquisa tem algumas limitações, as análises apresentadas na seção anterior não podem ser generalizadas para a população dado o pequeno número de respondentes; (2) a análise restringiu-se à visão de profissionais preponderantemente da área de Recursos Humanos e localizados no estado de São Paulo; (3) não foi possível verificar, para todos os respondentes, quais porcentuais da remuneração variável são relacionados ao alcance das metas globais da empresa, ao desempenho das áreas e ao desempenho pessoal; 4) não foi possível identificar as metas que são provenientes do Sistema de Controle Gerencial, possivelmente por se tratar de informações confidenciais e estratégicas das organizações pesquisadas. Como aspecto a ser destacado, pode-se dizer que embora o número de empresas pesquisadas seja pequeno, essas empresas têm forte presença no panorama econômico do Brasil, vez que 19 das 21 empresas pesquisadas constam do ranking dos 200 maiores grupos econômicos do Brasil, o que é bastante relevante em termos de representatividade.

Apesar dessas limitações, o estudo mostra que há um campo a ser explorado de forma mais abrangente em estudos futuro e que os objetivos propostos pela pesquisa foram cumpridos. Sugere-se, para pesquisas posteriores, que a pesquisa seja conduzida junto a profissionais da área de Controladoria, vez que estes estão diretamente relacionados ao Sistema de Controle Gerencial. Esta proposta é coerente com a percepção de que as áreas de Recursos Humanos e Controladoria precisam caminhar juntas em aspectos relacionados à avaliação da contribuição das pessoas à organização e também em relação aos efeitos do uso do Sistema de Controle Gerencial no processo decisório dos gerentes e no desempenho econômico das organizações. 


\section{Referências}

ANTHONY, Robert N.; GOVINDARAJAN, Vijay. Sistemas de Controle Gerencial. São Paulo: Atlas, 2002.

ARCHER, Earnest R.; O mito da motivação. In BERGAMINI, Cecília W. CODA, Roberto. Psicodinâmica da Vida Organizacional - Motivação e Liderança. 2. ed.. São Paulo: Atlas. 1997.

ASSAF NETO, Alexandre. Finanças Corporativas e Valor. 2. ed.. São Paulo: Atlas, 2006

BROOKING, Annie. Intellectual Capital: core asset for the third millenium enterprise. Boston: Thompson Publishing, 1996.

DAVIS, Keith; NEWSTROM, John W. Comportamento Humano no Trabalho. São Paulo: Pioneira. 1992.

DEMO, Pedro. Metodologia do Conhecimento Científico. São Paulo: Atlas, 2000 .

ETHERINGTON, L.; TJOSVOLD, D. Managing budget conflicts: Contribution of goal interdependence and interaction. Revue Canadienne des Sciences de l'Administration; Jun 1998; 15, 2.

FREZATTI, Fábio; AGUIAR, Andson A. The Use of EBITDA for Management Control: Potential Distortions and Limitations. Anais 5th International Conference on Theory and Practice in Performance Measurement and Management. Londres, 2006.

GARRISON, Ray H.; NOREEN, Eric W. Contabilidade Gerencial. 9. ed.. Rio de Janeiro: LTC, 2001.

HERZBERG, Frederick. Novamente: como se faz para motivar funcionários?. In BERGAMINI, Cecília W. CODA, Roberto. Psicodinâmica da Vida Organizacional - Motivação e Liderança. 2. ed. São Paulo: Atlas. 1997.

HOPE, Jeremy; FRASER, Robin. Who need budgets? Harvard Business Review. February, 2003.

HORNGREN, Charles T.; SUNDEM, Gary L.; STRATTON, William O. Contabilidade Gerencial. 12 ed. São Paulo: Pearson Education do Brasil, 2004.

IVANCEVICH, John M. Human resource management. 10a.ed.. New York: 
McGraw-Hill. 2007.

JENSEN, Michel.C. Paying People to Lie: the Truth about the Budgeting Process. European Financial Management, v. 9, p.379-406, 2003

LOPES, Alexsandro B. A teoria dos contratos, governança corporativa e contabilidade. in IUDÍCCIBUS, Sérgio de; LOPES, Alexsandro B. (org.). Teoria Avançada da Contabilidade. São Paulo: Atlas, 2004.

MERCHANT, Kenneth A.; VAN der STEDE, Win A. Management Control Systems : Performance Measurement, Evaluation and Incentives. Pearson, 2007.

MILKOVICH, George T.; BOUDREAU, John W. Administração de Recursos Humanos. São Paulo: Atlas, 2000.

OSTERLOH, M.; FREY, B.S. Does pay for performance really motivate employees?. In: NELLY, A. (org.) Business Performance measurement: Theory and practice. Cambridge University Press: 2002.

PERRY, James L.; PORTER, Lyman W.; Factors Affecting the Context for Motivation in Public Organizations. IN Academy of Management Review, 1982, v.7, n.1, p.89-98.

ROBBINS, Stephen P. Comportamento Organizacional. 9. ed.. São Paulo: Prentice-Hall, 2004.

SAMPAIO, Jader dos Reis. O Maslow desconhecido: uma revisão de seus principais trabalhos sobre motivação. Anais do XXVIII EnANPAD, Curitiba (PR), 25 a 29 de setembro. 2004

SIMONS, Robert. Performance Measurement and Control Systems for Implementing Strategy. Prentice Hall: New Jersey, 348 p, 2000.

VASCONCELOS, Flávio. C.; BRITO, Luiz A. L. Vantagem Competitiva: O construto e a Métrica. Revista de Administração de Empresas. São Paulo, FGV, v. 44, n.2, p.51-63, 2004.

VROOM, Victor H. Work and motivation. New York: John Wiley \& Sons, Inc. 1964.

WEITEN, Wayne. Introdução à Psicologia - temas e variações. São Paulo: Pioneira Thomson, 2002. 
